\title{
Comparação de parâmetros bióticos e abióticos entre fragmento de floresta secundária e reflorestamento de Araucaria angustifolia (Bertol.) O. Kuntze
}

\section{Comparison of biotics and abiotics parameters in a secondary forest fragment and a reforestation of Araucaria angustifolia (Bertol.) O. Kuntze}

\author{
Paulo Souza Medri ${ }^{1,3^{*}}$; Talita Parpinelli Ferracinn ${ }^{2,3}$; Valéria Teodoro da Silva ${ }^{1,3}$; Jose \\ Marcelo Domingues Torezan ${ }^{2,3}$; Jose Antonio Pimenta ${ }^{1,3}$; Edmilson Bianchini ${ }^{1,3}$
}

\section{Resumo}

O objetivo do trabalho foi comparar parâmetros bióticos e abióticos entre remanescente florestal e reflorestamento de Araucaria angustifolia (Bertol.) O. Kuntze, ambos localizados na Fazenda Monte Alegre no município de Telêmaco Borba - PR. Foram avaliados altura, o diâmetro à altura do peito (DAP) e a área basal (AB) das espécies arbóreas; pH e compactação do solo; cobertura de herbáceas, cobertura de dossel, espessura de serapilheira e temperatura e umidade relativa do ar. O estudo apontou similaridades entre os sítios amostrados, como a densidade de indivíduos, a estrutura de tamanho da vegetação, as áreas basais, $\mathrm{pH}$, umidade do ar e diferiu quanto à cobertura de dossel, a presença de herbáceas, a espessura de serapilheira, compactação do solo e a temperatura. Apesar das diferenças entre as áreas, não se observaram diferenças na estrutura da vegetação. Conclui-se que, com o tempo, não haverá diferenças entre os sítios.

Palavras-chave: Reflorestamento. Araucária. Abiótico. Densidade e serapilheira.

\begin{abstract}
This work aimed at comparing a native secondary forest fragment and an abandoned Araucaria angustifolia (Bertol.) Kuntze reforestation through biotic and abiotic parameters. The study sites are located at Fazenda Monte Alegre in Telêmaco Borba, Paraná, Brazil. Height and stem diameter at $1.30 \mathrm{~m}$ from soil and basal area of all tree species were recorded as well as $\mathrm{pH}$ and soil humidity, soil compaction, herb cover, canopy cover, litter thickness, air temperature and relative humidity. The study highlighted similarities between the sites sampled such as individuals density, vegetation size structure, basal areas, $\mathrm{pH}$, air humidity and differences in canopy cover, herbaceous cover, litter thickness, soil compaction and temperature. Despite the differences between the areas, there were no differences in the structure of vegetation. It was concluded that, with time, there will not be differences between the sites.
\end{abstract}

Key words: Reforestation. Araucaria. Abiotic. Density and litter.

\footnotetext{
1 Laboratório de Ecologia Vegetal, Departamento de Biologia Animal e Vegetal, Centro de Ciências Biológicas, Universidade Estadual de Londrina (UEL); C. P.: 6001, CEP: 86051-970 - Londrina-PR. E-mail: paulomedri@hotmail.com

2 Laboratório de Biodiversidade e Restauração de Ecossistemas, Departamento de Biologia Animal e Vegetal, Centro de Ciências Biológicas, Universidade Estadual de Londrina (UEL). Londrina-PR.

3 Programa de Pós Graduação em Ciências Biológicas, Universidade Estadual de Londrina (UEL). Londrina-PR.
} 


\section{Introdução}

A conversão de florestas em habitats antropogênicos é uma ameaça para a biodiversidade florestal do planeta. Devido às práticas agressivas de manejo normalmente envolvidas na silvicultura, a substituição de florestas por plantios florestais comerciais pode ser quase tão danosa quanto às atividades agropecuárias ou ocupações urbanas sem ter, no entanto, potencial destrutivo tão óbvio (NOSS; COOPERRIDER, 1994).

No entanto, em locais ou situações em que fatores socioeconômicos impedem as atividades de restauração, a escolha das espécies plantadas em um reflorestamento pode ser feita com uma abordagem comercial (LAMB et al., 1997). Keenan et al., (1997) propuseram algumas alternativas para o manejo sustentável de plantios florestais comerciais, buscando a manutenção de sub-bosque regenerante e a conseqüente conservação da diversidade biológica ali presente.

Desta forma, o uso de monoculturas florestais para o restabelecimento da riqueza de espécies em áreas degradadas pode se tornar uma alternativa viável (SILVA, 1995 apud BARBOSA, 2006). Silva Junior et al. (1995) estudando monocultura de Eucalyptus grandis W. Hill ex Maiden, concluíram que as árvores plantadas atuaram como espécies pioneiras como fariam em situações naturais, e possibilitam a colonização por espécies nativas

Engel e Parrot (2003) propuseram que a estrutura florestal, mesmo que constituída por monoculturas, tem impacto direto sobre o microclima, e é, assim, um importante fator para a continuidade dos processos sucessionais e para o restabelecimento dos processos do ecossistema. Dessa forma, as mudanças na estrutura florestal dos reflorestamentos devem aumentar a similaridade desses com florestas naturais.

Estudos com reflorestamento de araucária de diferentes idades realizados por Barbosa (2006) indicam que esta espécie agrega um número considerável de espécies em seu sub-bosque.
Porém, o mesmo autor afirma que a grande maioria encontrada por eles foram espécies heliófilas, as quais são resultado de anos de manutenção que impediram o estabelecimento de um dossel mais denso sob as araucárias.

Frente ao exposto, o uso de monoculturas florestais e o manejo adequado que permita o restabelecimento de riqueza de espécies em áreas degradadas se torna uma alternativa para a ecologia da restauração (BARBOSA, 2006).

Dados da estrutura vegetal, como a altura e a estrutura de copa das árvores nos reflorestamentos, podem-nos informar tanto sobre à autosustentabilidade destes, bem como predizer se estes estão aptos para dar suporte a novas etapas de sucessão (SUGANUMA, 2008).

O presente estudo visa a identificar diferenças bióticas e abióticas entre um reflorestamento de Araucaria angustifolia (Bertol.) O. Kuntze implantada em 1949 e um fragmento de floresta secundária. $\mathrm{O}$ estudo permite ainda avaliar o potencial de reflorestamentos comerciais na conservação da biodiversidade.

Foram levantadas duas hipóteses:

-A estrutura de um fragmento de floresta secundária difere da estrutura de um reflorestamento de Araucaria angustifolia.

- Parâmetros ambientais em um fragmento secundário diferem daquelas de um reflorestamento de araucária.

\section{Materiais e métodos}

O estudo foi desenvolvido em março de 2008 na Fazenda Monte Alegre $\left(24^{\circ} 12^{`} \mathrm{~S}, 50^{\circ} 33^{\prime} \mathrm{W}, 885 \mathrm{~m}\right.$ de altitude), no município de Telêmaco Borba, região centro-leste do Estado do Paraná (Figura 1). A fazenda, de propriedade da Empresa de Papel e Celulose Klabin S.A., possui a grande maioria de sua área de 126.737 ha coberta por monoculturas de Eucalyptus sp., Pinus sp. e Araucaria angustifolia. 
As áreas de floresta cobrem cerca de 52.000 ha e ocorrem em blocos dispersos pela propriedade que são ligados por florestas ciliares. $O$ uso do solo em grande parte das propriedades no entorno encontram-se imersos em uma matriz florestal, ou seja, a paisagem dominante é florestal.

Na paisagem local, observam-se três diferentes unidades vegetacionais naturais: a Floresta Estacional Semidecidual, a Floresta Ombrófila Mista e pequenas manchas de Campos. Essa paisagem é formada por um mosaico desses tipos florestais e campestre juntamente com reflorestamentos de Pinus sp., Eucalyptus sp. e A. angustifolia (AZEVEDO et al., 2008).

O tipo climático local é o $\mathrm{Cfa} / \mathrm{Cfb}$ (misto) subtropical úmido com verão quente a moderadamente quente e invernos úmidos e frios. A média pluviométrica anual é de $1700 \mathrm{~mm}$ e a média anual de temperatura é de $19,5^{\circ} \mathrm{C}$ (MENDONÇA; DANNI-OLIVEIRA, 2002).

A área caracterizada como fragmento secundário apresenta poucos indivíduos centenários, já que este foi alvo de extrativismo durante a colonização da região, e algumas clareiras com abundante presença de herbáceas. O fragmento está localizado no Parque Ecológico, o qual é uma área de preservação (Figura 1). O reflorestamento de araucária estudado foi plantado manualmente em julho de 1949 a um espaçamento de 1,2 x 0,8 metros. Algumas práticas de manejo foram realizadas: em 1950 e 1951 limpeza com enxada e as interferências de 1962, 1967, 1972, 1983 e 1989 foram para a extração de indivíduos adultos. Portanto, o talhão está a 19 anos sem grandes interferências antrópicas.

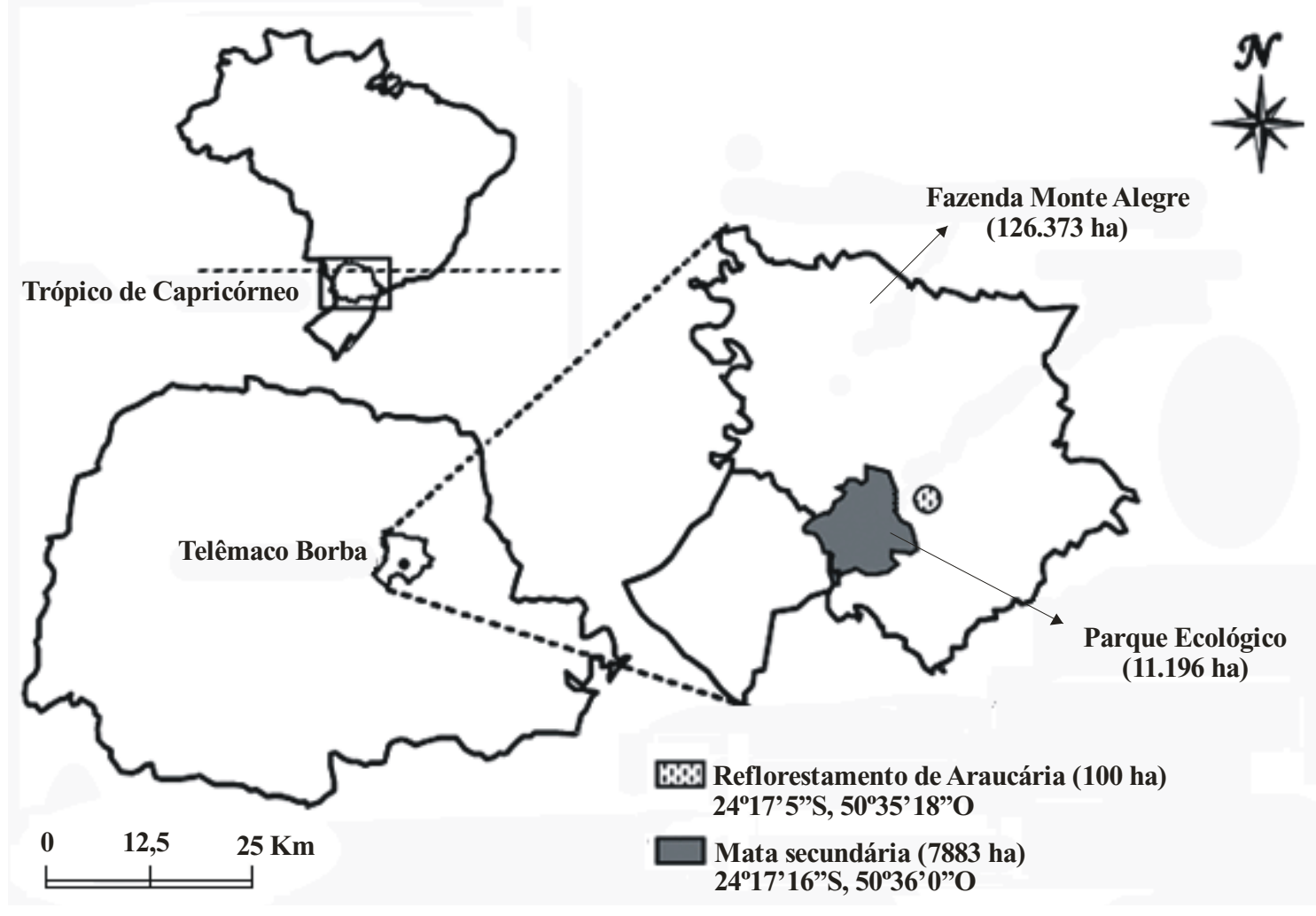

Figura 1. Localização do município de Telêmaco Borba, da fazenda Monte Alegre, do Parque Ecológico da Klabin e dos pontos onde foram realizadas as coletas. 
As coletas de dados foram realizadas em quatro parcelas de $10 \mathrm{~m} \times 10 \mathrm{~m}$ no reflorestamento de araucária e quatro no fragmento florestal, totalizando $400 \mathrm{~m}^{2}$ em cada sítio de estudo. As parcelas foram alocadas em área de aparência homogênea. Foram tomados dados de:

- Umidade e pH do solo: foram avaliados com um medidor portátil, tomando-se quatro medidas por parcela.

- Cobertura de herbáceas: as parcelas foram divididas em quatro quadrantes e, em cada um, foi estimada visualmente, em termos percentuais, a cobertura do estrato herbáceo.

- Cobertura do dossel: foi determinada, em porcentagem, com densiômetro esférico (LEMMON, 1956). Realizaram-se quatro medidas por parcela, posicionandose no centro da mesma e tomando uma medida voltada para cada um dos vértices (BIANCHINI; PIMENTA; SANTOS, 2001).

- Compactação do solo: foi estimada por meio da medida da força, em MPa, necessária à penetração de uma ponta de prova, com um penetrômetro portátil de solo. Foram dez medidas distribuídas aleatoriamente por parcela.

- Espessura da serapilheira: as medidas foram feitas com fita métrica. O método consiste em cortar a serapilheira, em um único movimento, com uma ferramenta cortante que penetra no solo. Sem retirar a ferramenta, empurra-a para um dos lados e expõe o perfil aberto pelo corte. Esse método permite medir, em centímetros, a altura da necromassa. A espessura foi determinada em seis pontos regularmente distribuídos em cada parcela.

- Temperatura $\left({ }^{\circ} \mathrm{C}\right)$ e umidade relativa do ar (\%): foram registradas por coletores de dados eletrônicos automáticos, instalandose três em cada área.

- Avaliação da estrutura florestal: foram amostrados todos os indivíduos com DAP maior ou igual a $2,5 \mathrm{~cm}$. Desses indivíduos, foram medidos o diâmetro a $5 \mathrm{~cm}$ do solo (DB), utilizado para o cálculo de área basal e o diâmetro a altura do peito (DAP - 1,30 $\mathrm{m}$ do solo). A altura dos indivíduos foi medida com uma fita métrica ou estimada visualmente com o auxílio de uma estrutura de altura conhecida. Foram realizadas duas análises diferenciadas para área basal. A primeira delas considerando todos os indivíduos amostrados e a outra, desconsiderando indivíduos com DB acima de $38 \mathrm{~cm}$, em ambas as áreas (fragmento florestal e reflorestamento de $A$. angustifolia.). Essa exclusão de indivíduos foi realizada para avaliar a área basal dos regenerantes, pois os indivíduos que tiveram DB acima de $38 \mathrm{~cm}$ foram provavelmente plantados no reflorestamento. Para comparar, utilizou-se o mesmo procedimento para a floresta secundária.

Os dados foram analisados por meio de comparações entre médias e erro padrão de cada parâmetro avaliado. Para verificar se houve diferença na estrutura de tamanho dos indivíduos entre as áreas, foi utilizado o teste de KolmogorovSmirnov (SIEGEL, 1975).

A estrutura de tamanho da vegetação foi calculada, dividindo-se os indivíduos em classes de altura e em classes de diâmetro.

\section{Resultados}

Foram amostrados 125 indivíduos arbóreos na floresta secundária e 118 no reflorestamento, o que representa uma densidade média de 3125 e 2925 indivíduos por hectare, respectivamente, com diâmetro à altura do peito igual ou maior que $2,5 \mathrm{~cm}$ (Figura 2). 


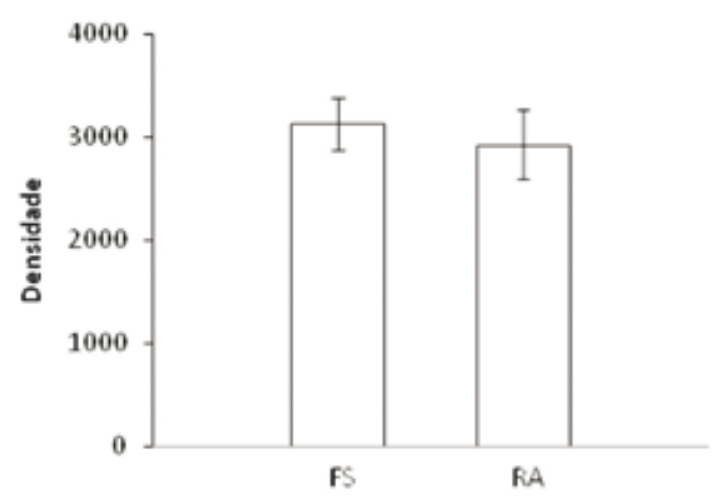

Figura 2. Comparação entre densidade média de indivíduos (número de indivíduos por hectare) em fragmento de floresta secundária(FS) e emreflorestamento de araucária (RA) na Fazenda Monte Alegre, Telêmaco Borba, PR.

Foi observado que, tanto na floresta secundária quanto no reflorestamento de araucária, $50 \%$ ou mais dos indivíduos estavam concentrados na primeira classe de tamanho, com redução nas classes subseqüentes, caracterizando curvas exponenciais negativas (Figura. 3). As curvas não diferiram entre as áreas $(\mathrm{p}>0,05)$.

Não foram observadas diferenças significativas na área basal total ou com a exclusão dos indivíduos maiores, entre os sítios estudados (Figura 4). Entretanto, deve-se salientar que, após a exclusão dos indivíduos maiores, o valor de área basal foi maior para o reflorestamento de araucária.
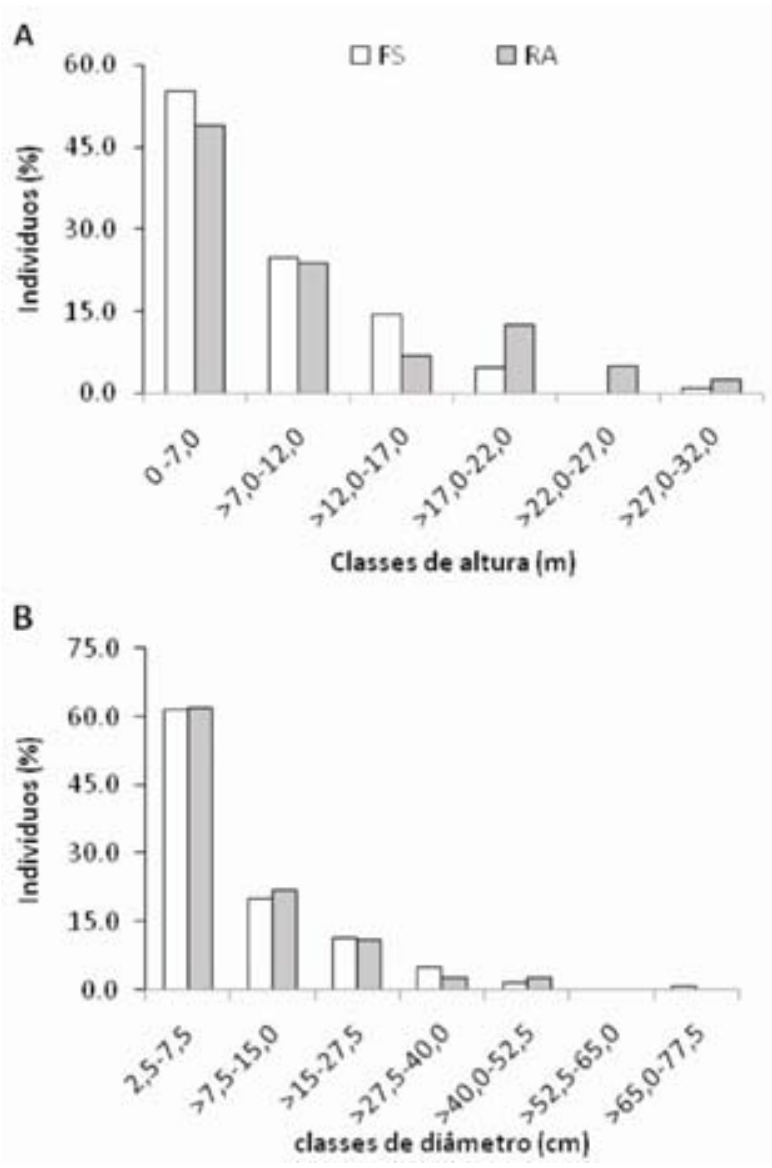

Figura 3. Porcentagem de indivíduos distribuídos entre classes de altura (A) e de diâmetro a altura do peito (DAP) (B) em fragmento de floresta secundária (FS) e em reflorestamento de araucária (RA) na Fazenda Monte Alegre, Telêmaco Borba, PR.

O dossel do reflorestamento de araucária foi mais aberto que o fragmento de floresta secundária (Figura 5).

A cobertura do solo por herbáceas foi maior na floresta secundária (Figura 6) e a serapilheira foi mais espessa na floresta secundária que no reflorestamento de araucária (Figura 7). Não foram observadas diferenças significativas no $\mathrm{pH}$ e na umidade do solo entre os sítios estudados (Figuras $8,9)$.

A compactação média do solo da floresta secundária foi significativamente menor que aquela do reflorestamento (Figura 10). 


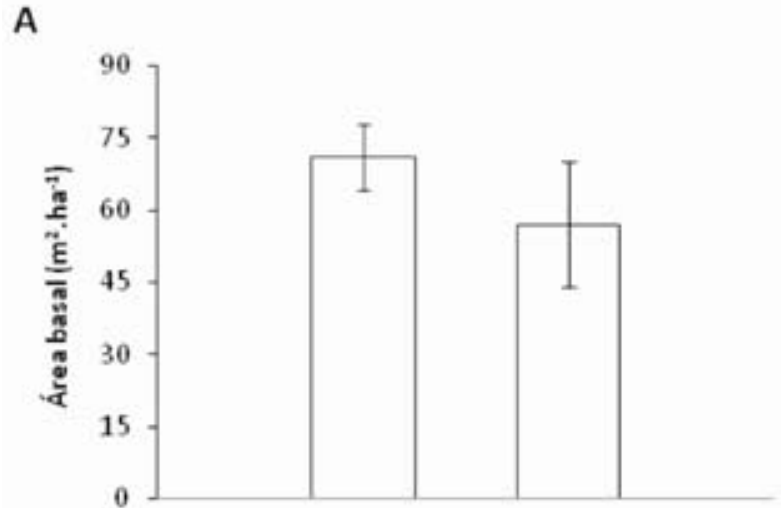

B

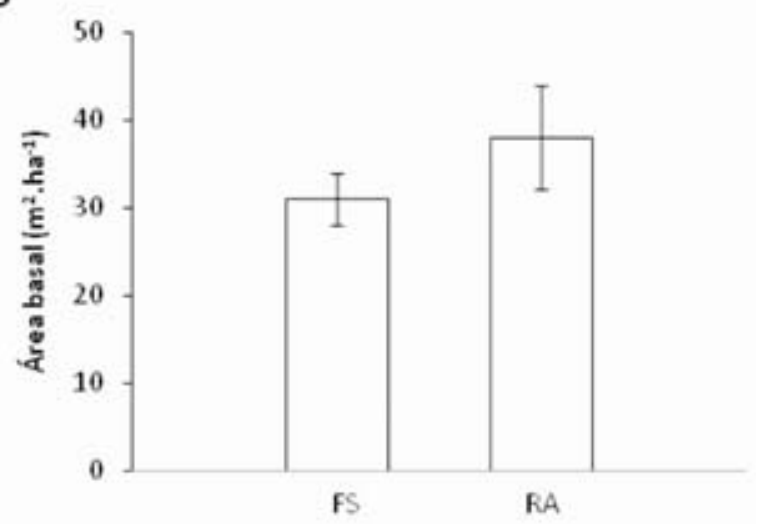

Figura 4. Áreas basais médias $\left(\mathrm{m}^{2} \cdot \mathrm{ha}^{-1}\right)$, considerando todos os indivíduos amostrados (A) e com a exclusão dos indivíduos com diâmetro acima de $38 \mathrm{~cm}$ (B) em fragmento de floresta secundária(FS) e em reflorestamento de araucária (RA) na Fazenda Monte Alegre, Telêmaco Borba, PR.

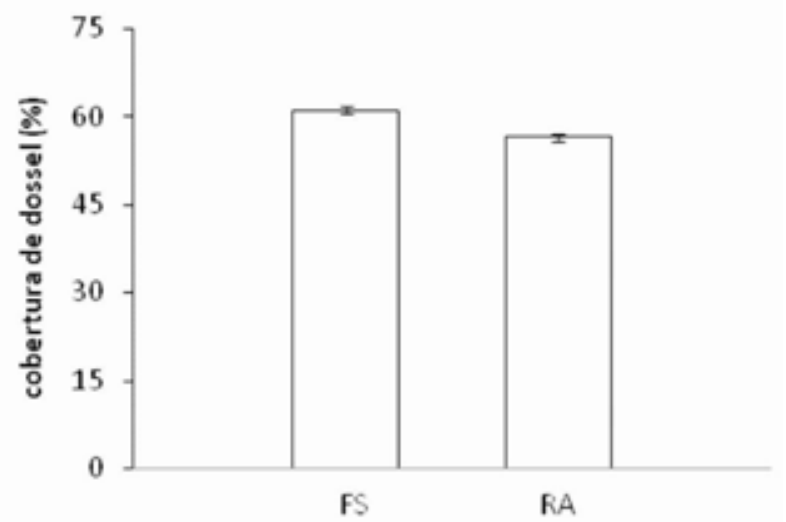

Figura 5. Porcentagens de cobertura de dossel (\%) em fragmento de floresta secundária(FS) e em reflorestamento de araucária (RA) na Fazenda Monte Alegre, Telêmaco Borba, PR.

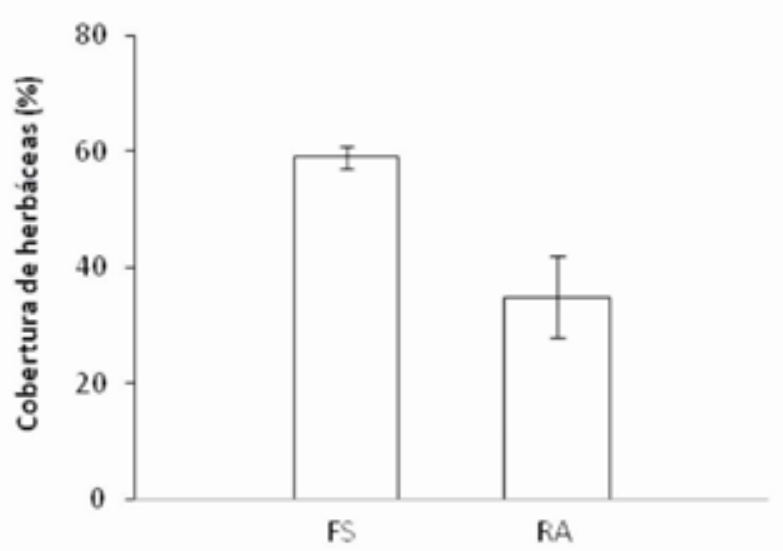

Figura 6. Porcentagem de cobertura do solo por espécies herbáceas em fragmento de floresta secundária (FS) e em reflorestamento de araucária (RA) na Fazenda Monte Alegre, Telêmaco Borba, PR.

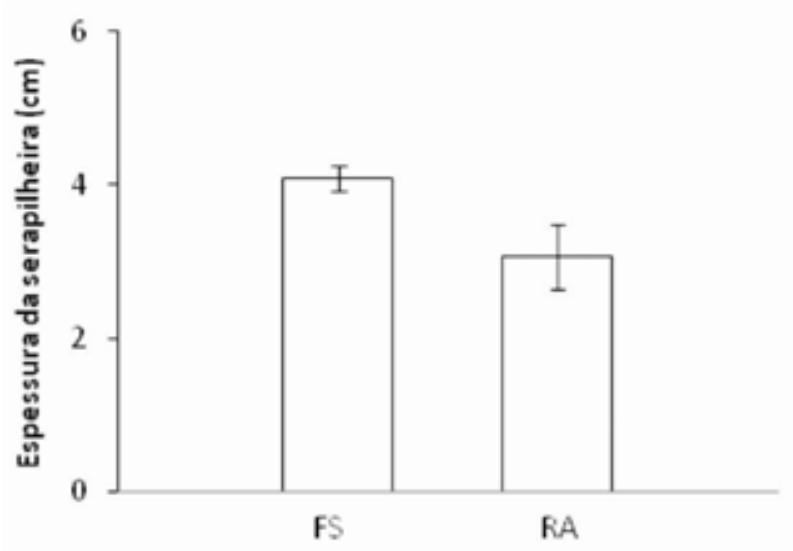

Figura 7. Espessura média da serapilheira $(\mathrm{cm})$, em fragmento de floresta secundária(FS) e em reflorestamento de araucária (RA) na Fazenda Monte Alegre, Telêmaco Borba, PR.

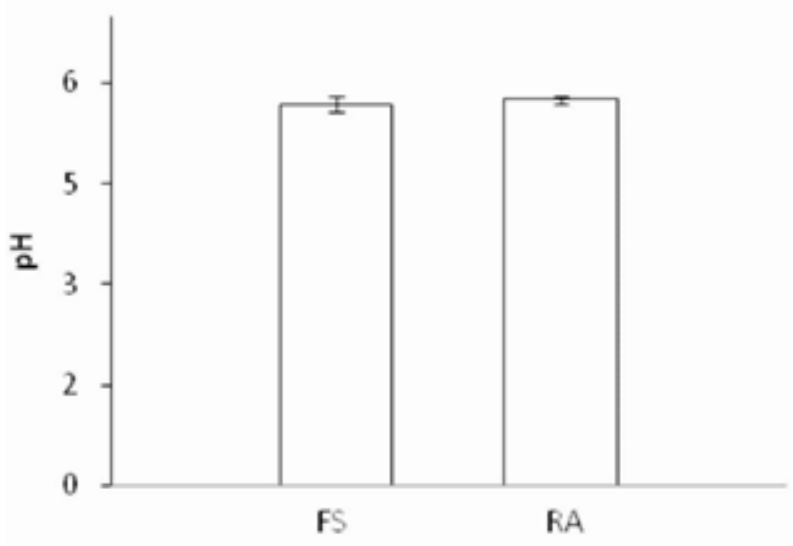

Figura 8. Valores médios de $\mathrm{pH}$, em fragmento de floresta secundária (FS) e em reflorestamento de araucária (RA) na Fazenda Monte Alegre, Telêmaco Borba, PR. 


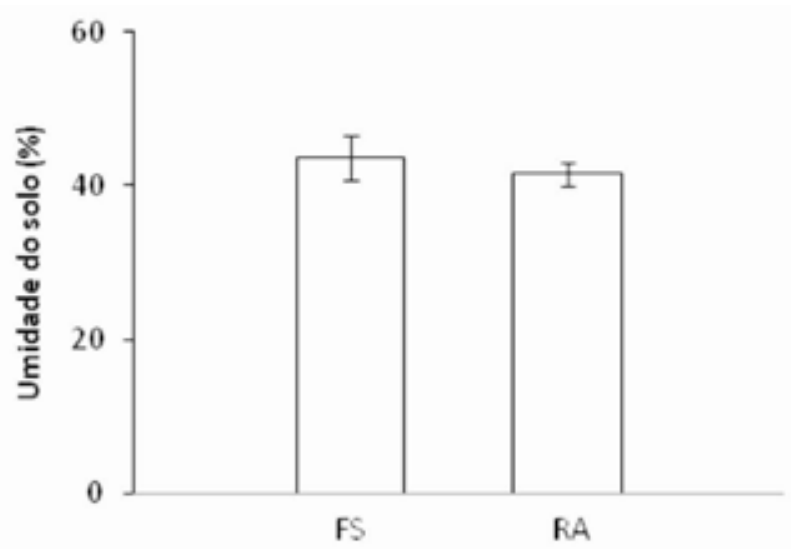

Figura 9. Valores médios da umidade do solo (\%), em fragmento de floresta secundária(FS) e em reflorestamento de araucária (RA) na Fazenda Monte Alegre, Telêmaco Borba, PR.

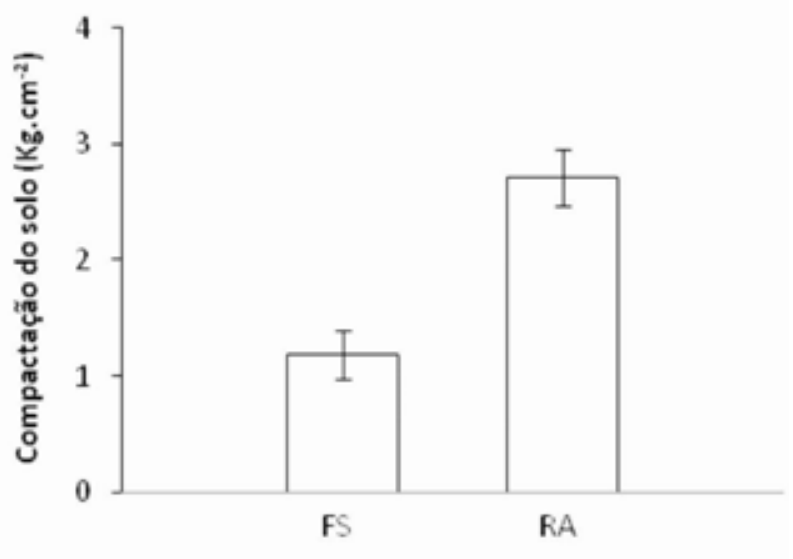

Figura 10. Valores médios da compactação do solo (Kg. $\mathrm{cm}^{-2}$ ), em fragmento de floresta secundária (FS) e em reflorestamento de araucária (RA) na Fazenda Monte Alegre, Telêmaco Borba, PR.

As temperaturas médias diárias e a amplitude térmica diária média foram maiores para o fragmento de floresta secundária (Figuras 11 e 12). A umidade relativa do ar, tanto noturna quanto diurna, foram maiores para o reflorestamento de araucária (Figura 13).

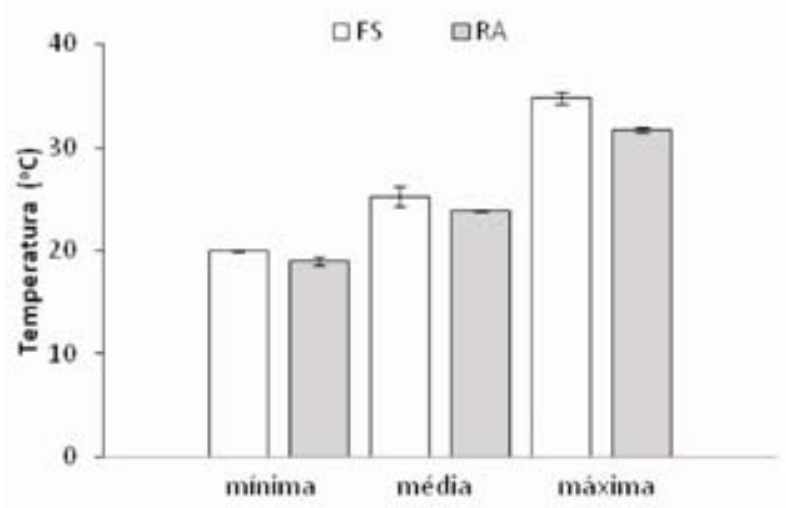

Figura 11. Valores médios da temperatura mínima, média e máxima diária $\left({ }^{\circ} \mathrm{C}\right)$ em fragmento de floresta secundária (FS) e em reflorestamento de araucária (RA) na Fazenda Monte Alegre, Telêmaco Borba, PR.

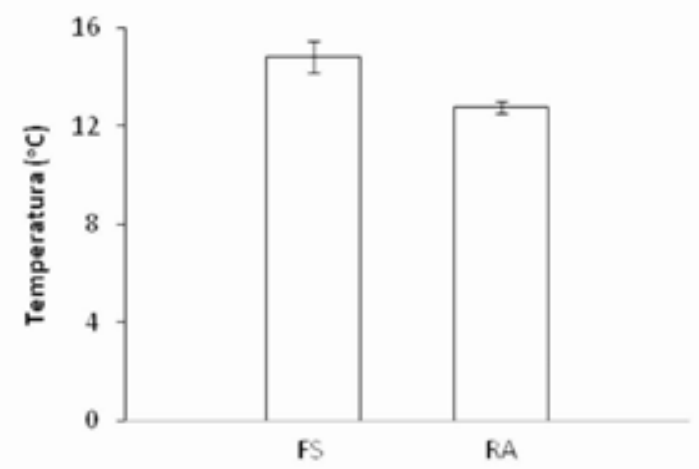

Figura 12. Valores médios da amplitude da temperatura $\left({ }^{\circ} \mathrm{C}\right)$ em fragmento de floresta secundária (FS) e em reflorestamento de araucária (RA) na Fazenda Monte Alegre, Telêmaco Borba, PR.

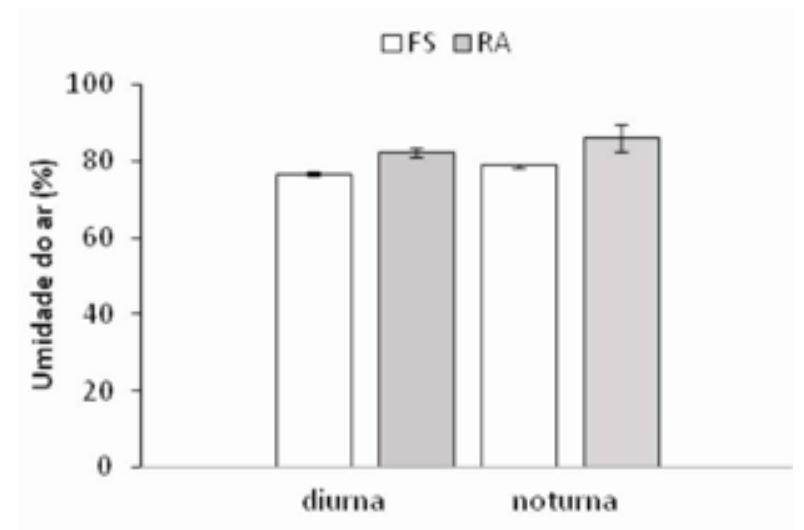

Figura 13. Valores médios de umidade diária do ar noturna e diurna (\%) em fragmento de floresta secundária (FS) e em reflorestamento de araucária (RA) na Fazenda Monte Alegre, Telêmaco Borba, PR. 


\section{Discussão}

As estruturas de tamanho observadas seguem o padrão de "J-invertido", o que indica capacidade de regeneração (RUBIN et al., 2005 apud SUGANUMA, 2008) e é característica de florestas heterogêneas e multiâneas (RODE, 2008).

Resultados semelhantes foram encontrados por Sonego, Backes e Souza (2007), estudando Floresta Ombrófila Mista madura e por Rode (2008) em estudos com reflorestamentos de araucária de 60 anos e Floresta Ombrófila Mista.

O reflorestamento de araucária em estudo possui 59 anos e, a última limpeza efetuada no reflorestamento foi há 47 anos. A análise dos dados da vegetação indica que este tempo foi suficiente para que a regeneração da vegetação nativa no subosque do reflorestamento fosse similar àquela da floresta secundária. Salienta-se que a região de estudo representa a região de contato entre a Floresta Estacional Semidecidual e a Floresta Ombrofila Mista (floresta de araucária), ou seja, $A$. angustifolia faz parte da vegetação nativa da região (TOREZAN, 2002).

Barbosa (2006), em estudos com reflorestamento de araucária de diferentes idades, observaram que quanto mais antigo o reflorestamento, maior era a riqueza e a diversidade de Shannon. Estes autores encontraram 125 espécies nativas em seu subosque de reflorestamento de 43 anos de idade.

Estudos indicam que a cobertura de herbáceas está diretamente relacionada com a luminosidade que penetra no sub-bosque e inversamente com cobertura de copa (SUGANUMA, 2008). Porém, no presente estudo, observou-se maior quantidade de herbáceas na floresta que apresentou maior valor de cobertura de copa. Talvez este resultado seja reflexo dos manejos realizados, como o preparo do solo para o plantio das mudas de araucária com possível empobrecimento do mesmo, repercutindo em diferenças na ocupação das herbáceas.

A maior compactação do solo no reflorestamento pode ser conseqüência dos manejos realizados. A maior compactação do solo dificulta o crescimento das raízes em profundidade, fazendo com que se desenvolvam superficialmente, reduzindo o volume de solo explorado, o que pode elevar os riscos de deficiência hídrica e nutricional das plantas (MORAES; BENEZ; LIBARDI, 1995). Dessa forma, a compactação do solo pode estar relacionada com a menor cobertura de herbáceas no reflorestamento de araucária.

A floresta secundária apresentou serapilheira mais espessa que o reflorestamento de araucária, semelhante ao que foi observado por Suganuma (2008) ao comparar fragmento de floresta estacional e uma área reflorestada com espécies nativas. A queda das folhas é causada pela senescência, resultante de uma série de processos metabólicos ligados à fisiologia de cada espécies e também pelos estímulos vindos do ambiente, como fotoperíodo, temperatura, estresse hídrico etc. (SCHUMACHER et. al., 2004). Estes autores afirmam que a deposição de serapilheira é maior em regiões mais quentes. Portanto, a maior deposição de serapilheira apresentada no fragmento secundário corrobora estas afirmações.

O fragmento secundário apresentou maior variação de temperatura e menor umidade diurna e noturna, o que pode ser resultado da presença de clareiras, vizinhas as parcelas. Portanto, a estrutura florestal age com menor tamponamento, neste sitio, comparado ao reflorestamento de araucária.

\section{Conclusão}

Em termos gerais, a estrutura de tamanho do reflorestamento de A. angustifolia não diferiu da estrutura apresentada pelo fragmento de floresta secundária. Logo, a maior complexidade esperada para o fragmento florestal não foi observada. Entretanto, diferenças foram observadas em alguns parâmetros ambientais.

Conclui-se que, com o tempo, a estrutura do reflorestamento terá maior semelhança com a floresta remanescente da região e, por conseguinte menores diferenças serão observadas nos parâmetros ambientais. 


\section{Agradecimentos}

Os autores agradecem a empresa de papel e celulose Klabin S. A. por permitir a utilização de suas áreas para coleta de dados, assim como todo o suporte oferecido. Ao professor doutor José Lopes pelas valiosas discussões, informações e ajudas a campo. À Universidade Estadual de Londrina pelo apoio de infra-estrutura laboratorial, e à CAPES pelo apoio financeiro durante as coletas de campo.

\section{Referências}

AZEVEDO, T. I. N.; SEKIAMA, M. L.; VIEIRA, A. O. S.; BENNEMANN, S. T. Descrição física da micro bacia do Ribeirão Varanal e caracterização dos trechos. In: BENNEMAN, S. T.; SHIBATTA, O. A.; VIEIRA, A. O. S. A flora e a fauna do Ribeirão Varanal: um estudo da biodiversidade no Paraná. Londrina: EDUEL, 2008. Cap. 1, p. 06-14.

BARBOSA, C. E. A. A estrutura da paisagem e a diversidade de plantas em reflorestamento. 2006. Dissertação (Mestrado em Ciências Biológicas) - Curso de Pós-graduação em Ciências Biológicas, Universidade Estadual de Londrina, Londrina, 2006.

BIANCHINI, E.; PIMENTA, J. A.; SANTOS, F. A. M. Spatial and temporal variation in the canopy cover in a tropical semi-deciduous forest. Brazilian Archives of Biology and Technology, Curitiba, v. 44, n. 3, p. 269-276, 2001.

ENGEL, V. L.; PARROTTA, J. A. Definindo a restauração ecológica: tendências e perspectivas mundiais. In: KAGEYAMA, P. Y.; OLIVEIRA, R. E.; MORAES, L. F. D.; ENGEL V. L.; GANDARA, F. B. Restauração Ecológica de Ecossistemas Naturais. Botucatu: FEPAF, 2003. p. 01-26.

KEENAN, R.; LAMB, D.; WOLDRING, O.; IRVINE, T.; JENSEN, R. Restoration of plant biodiversity beneath tropical tree plantations in northern Australia. Forest Ecology and Managemen, Amsterdam, v. 99, n. 1, p. 117-131, 1997.

LAMB, D.; PARROTA, J.; KEENAN, R.; TUCKER, N. Rejoining habitat remnants: restoring degraded rainforest lands. In: LAURANCE, W. F.; BIORREGAARD JUNIOR, R. O. Tropical Forest remnants. Chicago: The University of Chicago Press, 1997. p. 366-385.

LEMMON, P. E. A spherical densiometer for estimating forest overstory density. Forest Science, Lawrence, v. 2, n. 4, p. 313-320, 1956.
MENDONÇA, F. A.; DANNI-OLIVEIRA, E. I. M. Dinâmica atmosférica e tipos climáticos predominantes da bacia do Rio Tibagi. In: MEDRI, M. E.; BIANCHINI, E.; SHIBATTA, O. A.; PIMENTA, J. A.. A bacia do Rio Tibagi. Londrina: Edição dos editores, 2002. Cap. 4, p. 63-66.

MORAES, M. H.; BENEZ, S. H.; LIBARDI, P. L. Efeitos da compactação em algumas propriedades físicas do solo e seu reflexo no desenvolvimento das raízes de plantas de soja. Bragantia, Campinas, v. 54, n. 2, p. 393-403, 1995.

NOSS, R. F.; COOPERRIDER, A. Y. Saving Nature's Legacy: protecting and restoring biodiversity. Washington: Island Press, 1994. 443 p.

RODE, R. Avaliação florística e estrutural de uma floresta ombrófila mista e de uma vegetação arbórea estabelecida sob um povoamento de Araucaria angustifolia de 60 anos. 2008. Dissertação (Mestrado em Engenharia Florestal) - Curso de Pós - Graduação em Engenharia Florestal, Universidade Federal do Paraná, Curitiba, 2008.

SCHUMACHER, M. V.; BRUN, E. J.; HERNANDES, J. I.; KÖNING, F. G. Produção de serapilheira em uma floresta de Araucaria angustifolia (Bertol.) Kuntze no município de Pinhal Grande - RS. Revista Árvore, Viçosa, v. 28, n. 1, p. 29-37, 2004.

SIEGEL, S. Estatística não-paramétrica para as ciências do comportamento. São Paulo: McGraw-Hill, 1975.

SILVA JUNIOR, M. C.; SCARANO, F. R.; SOUZA, F. C. Regeneration of an Atlantic Forest formation in the understorey of a Eucalyptus grandis plantation in south eastern Brazil. Journal of Tropical Ecology, New York, v.11, n. 1, p. 147-152, 1995.

SONEGO, R. C.; BACKES, A.; SOUZA, A. F. Descrição da estrutura de uma Floresta Ombrófila Mista, RS, Brasil, utilizando estimadores não-paramétricos de riqueza e rarefação de amostras. Acta Botanica Brasílica, Porto Alegre, v. 21, n. 4, p. 943-955, 2007.

SUGANUMA, M. S. Avaliação de sucesso da restauração florestal baseada em estrutura florestal e processos do ecossistema. 2008. Dissertação (Mestrado em Ciências Biológicas) - Curso de Pós-graduação em Ciências Biológicas, Universidade de Londrina, Londrina, 2008.

TOREZAN, J. M. D. Nota sobre a vegetação da bacia do Rio Tibagi. In: MEDRI, M. E.; BIANCHINI, E.; SHIBATTA, O. A.; PIMENTA, J. A. A bacia do Rio Tibagi. Londrina: Edição dos editores, 2002. Cap. 7, p. 103-107. 
